\title{
Assessment of a Sensitive qPCR Assay Targeting a Multiple-Copy Gene to Detect Orientia tsutsugamushi DNA
}

\author{
Chien-Chung Chao ${ }^{1,2, *}$, Tatyana Belinskaya ${ }^{2}$, Zhiwen Zhang ${ }^{2}$, Le Jiang ${ }^{2}$ and Wei-Mei Ching ${ }^{1,2,+}$ \\ 1 Viral and Rickettsial Diseases Department, Infectious Diseases Directorate, Naval Medical Research Center, \\ Silver Spring, MD 20910, USA \\ 2 Department of Preventive Medicine and Biostatistics, Uniformed Services University of the Health Sciences, \\ Bethesda, MD 20814, USA \\ * Correspondence: chien-chung.c.chao.civ@mail.mil \\ + Deceased.
}

Received: 15 July 2019; Accepted: 29 July 2019; Published: 31 July 2019

\begin{abstract}
Scrub typhus is caused by an obligated intracellular organism, Orientia tsutsugamushi (Orientia). The disease was traditionally thought to be limited in the tsutsugamushi triangle. Recently, scrub typhus has been confirmed in areas outside the triangle. Serological diagnosis of scrub typhus relies on indirect immunofluorescence assay (IFA). Molecular assays such as PCR, qPCR, loop-mediated isothermal amplification, and recombinase polymerase amplification are often targeting a single copy gene. These assays are sensitive and specific, yet they are not broadly used in clinical settings possibly due to low circulating Orientia in blood. In this study, we compared qPCR results using a multiple copy (traD) gene with those using a single copy ( $47 \mathrm{kDa})$ gene to assess the improvement of sensitivity and limit of detection. Our results demonstrate that the qPCR using the traD gene provides superior sensitivity in 15 Orientia strains. The limit of detection is below single Orientia genome equivalent and the assay retains specificity with excessive DNA from mouse, chiggers and human. The clinical utility was evaluated using confirmed scrub typhus positive and negative samples. The results show $100 \%$ sensitivity and specificity in these samples suggesting that the traD gene qPCR may be useful for clinical diagnosis of Orientia infection.
\end{abstract}

Keywords: scrub typhus; Orientia tsutsugamushi; qPCR; traD gene; multiple copy gene; diagnosis

\section{Introduction}

Scrub typhus (ST) is an acute febrile illness caused by an obligate intracellular bacterium, Orientia tsutsugamushi (Orientia). The bacterium is transmitted to human via a bite by the larval stage (chigger) of Orientia harbored Leptotrobidium mite. The disease is prevalent in the tsutsugamushi triangle encompassing a broad Asia-Pacific region where over 1 billion people are at risk with estimated 1 million cases annually. Clinical manifestation of the disease varies from mild to severe with symptoms like eschar, fever, myalgia, maculopapular rash, lymphadenopathy, and coagulopathies that can result in circulatory system collapse [1,2]. The disease can contribute up to $20 \%$ of all acute undifferentiated febrile illnesses. Among the blood culture-negative fever patients, as high as $27 \%$ of these patients are scrub typhus positive [3-5]. The mortality of this high prevalence disease ranges from as low as $1.4 \%$ to as high as $70 \%$. The outcome of the disease depends upon patients' prior immune status, administration of proper antibiotics in a timely manner and the virulence of the Orientia strains [1,6-8]. Since the disease can be effectively treated by doxycycline, accurate and timely diagnosis can provide prompt treatment to alleviate fever and facilitate recovery of patients. The disease has recently been 
found outside the traditional triangle in places like Middle East, South America and Africa [9-12], highlighting the global need for a sensitive diagnostic assay.

There is no FDA cleared diagnostic assay that is commercially available. Serological assay, such as indirect immunofluorescence assay (IFA), has been the gold standard for diagnosis. However, it often requires paired sera collected weeks apart to confirm a four-fold titer increase for diagnosis. This serological assay not only suffers the high seroprevalence baseline among population in the endemic areas, it also cannot provide diagnosis in a timely fashion for prompt treatment. Therefore, various molecular assays targeting different Orientia-specific genes have been developed. These include qPCR/PCR assays detecting $47 \mathrm{kDa}$ [13], $56 \mathrm{kDa}$ [14], 16s rRNA [15], GroEL [16], and OmpA [17] genes, loop-mediated isothermal amplification (LAMP) assays detecting $47 \mathrm{kDa}$ [18] and GroEL genes [19], and recombinase polymerase amplification (RPA) assay targeting the $47 \mathrm{kDa}$ gene [20]. Keller et al. [21] have demonstrated that a multiple copy gene traD qPCR improves the sensitivity to detect Orientia DNA in a footpad infection mouse model. The utility of traD qPCR for clinical diagnosis has not been evaluated. Moreover, the specificity and sensitivity of the traD gene qPCR in various strains of Orientia has not been extensively studied. More recently, a multiplex qPCR assay targeting the $47 \mathrm{kDa}$ and GroEL genes was developed and evaluated for sensitive diagnosis of scrub typhus [22]. The authors concluded that $86.5 \%$ sensitivity and $100 \%$ specificity was achieved with the additional benefit of confirming scrub typhus patients in samples with inconclusive IFA results based on a single blood sample. These results suggest a multiplex qPCR assay can serve as a more sensitive assay to diagnose scrub typhus using just a single blood sample without the need to wait for convalescent serum for IFA confirmation.

This study aims to evaluate the performance of the traD qPCR assay originally developed by Keller et al. [21]. We demonstrated that the assay is broadly reactive to detect Orientia DNA from 15 strains previously isolated in the tsutsugamushi triangle. The detection limit was less than one Orientia genome equivalent. The sensitivity and specificity were not affected by the presence of chigger-mites, mouse or human genomic DNA. The assay was evaluated with a limited number of scrub typhus positive and negative samples and showed $100 \%$ sensitivity and specificity. Moreover, the assay was able to detect Orientia DNA in samples that were prior PCR negative but confirmed positive based on IFA. Taken together, the results demonstrate and confirm the clinical utility of traD-based qPCR for sensitive and specific detection of Orientia DNA.

\section{Materials and Methods}

\subsection{Sources of Orientia Genomic DNA}

Orientia DNAs used in this study were purified from three different sources as detailed below. The first set of DNA was genomic DNA extracted from renografin-purified whole cells of 15 different strains (Table 1). The second set of genomic DNA was extracted from two chigger-mite lines (Leptotrombidium chiangraiensis (Lc) and Leptotrombidum impalum (Li)) established in Armed Forces Research Institute of Medical Sciences (AFRIMS), Bangkok. The third set of DNA was extracted from liver of mice infected by chigger-mites as described by Ching et al. [23] under the animal protocol (PN \#12-12). The protocol was approved by the AFRIMS Institutional Animal Care and Use Committee and all procedures were conducted in compliance with the Animal Welfare Acts. Qiagen QIAmp DNA Mini kit (Qiagen, Germantown, MD, USA) was used for DNA extraction from whole cells suspension and mouse liver, and Invisorb Spin Tissue Mini kit from Stratec Molecular (Stratec Molecular, Berlin, Germany) was used to extract DNA from chigger-mites. Purification was performed according to the manufacturer protocols. DNA concentration was measured by NanoDrop 2000 Spectrophotometer (Thermo Fisher Scientific, Waltham, MA, USA) to ensure purity $\left(\mathrm{A}_{260} / \mathrm{A}_{280}>1.8\right.$ with concentration at least $>30 \mathrm{ng} / \mu \mathrm{L}$ ). The Orientia genome copy (or referred as genome equivalent, GE) of all extracted DNA was determined using qPCR targeting $47 \mathrm{kDa}$ as it is a known single copy gene in Orientia 
genome. Thus one copy of the $47 \mathrm{kDa}$ gene is one Orientia genome equivalent. This determined GE was used for sample preparation in all additional experiments when a designated GE sample was needed.

Table 1. Variation of number of copies of the traD gene in various Orientia genomes DNA.

\begin{tabular}{ccc}
\hline Orientia Isolate & Country of Origin & $\Delta \mathbf{C t}^{*}$ \\
\hline AFC-27 & Thailand & $8.29 \pm 0.72$ \\
$18-030641$ & Malaysia & $8.14 \pm 0.34$ \\
18-032029 & Malaysia & $8.70 \pm 1.24$ \\
AFC-12 & Thailand & $7.14 \pm 1.40$ \\
Gilliam & Burma & $5.09 \pm 0.32$ \\
MAK 119 & Taiwan & $4.60 \pm 0.35$ \\
MAK 243 & Taiwan & $9.17 \pm 1.03$ \\
Karp & New Guinea & $5.10 \pm 0.26$ \\
AFPL12 & Thailand & $7.54 \pm 0.49$ \\
TA763 & Thailand & $7.26 \pm 1.19$ \\
AFC-1 & Thailand & $8.30 \pm 0.34$ \\
Citrano & Australia & $7.68 \pm 1.63$ \\
Garton & Australia & $11.74 \pm 1.59$ \\
Boryong & South Korea & $5.40 \pm 0.13$ \\
Kato & Japan & $7.41 \pm 1.17$ \\
\hline
\end{tabular}

* The $\Delta \mathrm{Ct}$ was calculated by subtracting the cycle threshold $(\mathrm{Ct})$ values of the traD gene from that of the $47 \mathrm{kDa}$ gene for a given Orientia strain.

\section{2. qPCR Condition for Single Copy $47 \mathrm{kDa}$ Gene and Multiple Copy traD Gene}

The qPCR primer sets for the $47 \mathrm{kDa}$ (single copy) gene and the traD (multiple copies) gene were described before $[13,21]$. These primers were ordered from Eurofins MWG Operon (Louisville, KY, USA). Master mixes of QuantiFast SYBR Green PCR kit (Qiagen, Germantown, MD, USA) and RT SYBR Green Rox qPCR master mix (Qiagen, Germantown, MD, USA) were used for the multiple copy traD gene and the single copy $47 \mathrm{kDa}$ gene $\mathrm{qPCR}$, respectively. For each reaction, $0.5 \mu \mathrm{M}$ of each primer was added in a total volume of $20 \mu \mathrm{L}$ containing $2 \mu \mathrm{L}$ of extracted DNA template. The qPCR cycling condition used was $95^{\circ} \mathrm{C}$ for $10 \mathrm{~min}$ followed by 40 cycles of $95^{\circ} \mathrm{C}$ for $15 \mathrm{~s}$ and $60{ }^{\circ} \mathrm{C}$ for $60 \mathrm{~s}$ in a 7500 Fast Real-Time PCR System (Applied Biosystems, Foster City, CA, USA). The plasmids for the $47 \mathrm{kDa}$ and traD genes were prepared as described previously [20] and were used to generate copy number standard curves at a concentration range from $10^{5}$ to 10 copies/PCR reaction. All samples for standard curves were performed in duplicates. The qPCR efficiency for both genes varied between $90 \%$ to $105 \%$. RNase free water was used as a negative control for both genes.

\subsection{Comparison of Performance of Single-Copy Gene vs. Multiple-Copy Gene Using Genomic DNA}

Three different DNA sources were used to compare the results between the traD gene and the $47 \mathrm{kDa}$ gene qPCR. The concentration of DNA extracted from different strains of Orientia, or two different chigger-mites, or liver collected from Lc-infected mice was determined by the $47 \mathrm{kDa}$ qPCR as described previously. The concentration was adjusted to 200 copies/2 $\mu \mathrm{L}$ (i.e., 200 copies/qPCR reaction) then a serial of $1: 5$ dilution to achieve $200,40,8,1.6$ and 0.32 copies/qPCR reaction). The diluted DNA was added to qPCR reactions to quantitate the $47 \mathrm{kDa}$ and traD genes. The copy number of both genes at different concentration was determined using known copy number of standard $47 \mathrm{kDa}$ or traD plasmids. The cycle threshold $(\mathrm{Ct})$ values of both genes at each concentration were also determined and compared. The melting curve of each amplification was evaluated to ensure consistency between each sample and standard, this was particularly the case when $\mathrm{Ct}$ was close to or above 35 . When an inconsistent melting curve was observed for a given sample, the sample was considered as negative regardless of $\mathrm{Ct}$ value. The data is presented as $\Delta \mathrm{Ct}$ and was calculated by averaging the $\Delta \mathrm{Ct}$ of all dilutions or all replicates of the same dilution. For each dilution, the $\Delta \mathrm{Ct}$ was calculated by subtracting the $\mathrm{Ct}$ values of the traD gene from that of the $47 \mathrm{kDa}$ gene for a given Orientia strain. Additionally, 
genomic DNA isolated from pure Karp strain of Orientia with known copy number of the $47 \mathrm{kDa}$ gene was spiked in normal human plasma. The spiked samples were then subjected to DNA extraction. The extracted DNA was quantified by the $47 \mathrm{kDa}$ gene and traD gene qPCR. Each DNA preparation was prepared and analyzed independently in at least five replicates.

\subsection{Demonstration of Specificity of traD Gene qPCR}

Several genomic DNA from related bacteria included various Rickettsia and Anaplasma in $10^{5}$ copy $/ \mu \mathrm{L}$ was added to the $\mathrm{qPCR}$ reaction to determine if the traD gene was specific. Furthermore, the extracted DNA from Lc or Li chigger-mites, and Lc-infected mouse liver was used to demonstrate the specificity of the traD gene qPCR.

\subsection{Evaluation of traD qPCR Using DNA Extracted from Confirmed Scrub Typhus Positive and Negative Patient Blood}

To demonstrate the traD qPCR is sensitive and specific to detect Orientia DNA in scrub typhus confirmed patients, $2 \mu \mathrm{L}$ of extracted DNA from scrub typhus confirmed positive patients (by IFA, PCR or qPCR), healthy individuals or patients confirmed with other infectious diseases were included in the study (PJT-15-15).

\subsection{Statistical Analysis}

Data was analyzed using GraphPad Prism 7.0. The statistical analysis of $\Delta \mathrm{Ct}$ displayed in Figure 1 was performed using the procedure of Benjamini, Krieger, and Yekutieli with $Q=0.01$. $\Delta \mathrm{Ct}$ obtained at each DNA preparation was compared among all three different DNA sources (i.e., two different chigger-mites and chigger-infected mouse liver).

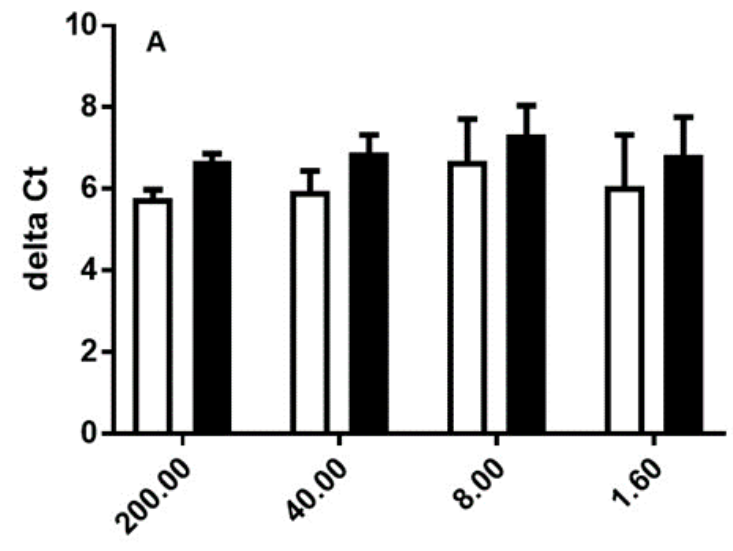

Genome Equivalent of DNA (copies/ $\mu$ L)

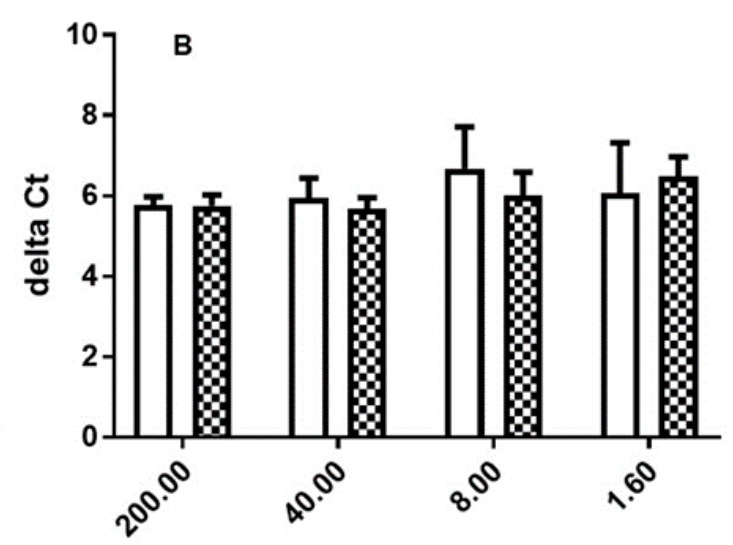

Genome Equivalent of DNA (copies/ $\mu \mathrm{L})$

Figure 1. Comparison of $\triangle \mathrm{Ct}$ in Orientia DNA using $\mathrm{Ct}$ determined by the $47 \mathrm{kDa}$ and traD $\mathrm{qPCR}$. Genomic DNA was extracted from Leptotrombidium chiangraiensis (Lc) (open bars in Panel A and B) chigger mites, Lc chiggers infected mouse liver (black bars in Panel A) or Leptotrombidum impalum (Li) (hashed bars in Panel B) chigger mites as described. The extracted DNA was diluted to the appropriate concentration according to the GE determined based on the $47 \mathrm{kDa}$ gene as described in Materials and Methods. $\Delta \mathrm{Ct}$ was calculated by subtracting the $\mathrm{Ct}$ determined using the traD gene from that determined using the $47 \mathrm{kDa}$ gene at a given GE. The difference in $\Delta \mathrm{Ct}$ between the DNA extracted from different sources was not statistically significant. 


\title{
3. Results
}

3.1. Multiple-Copy Gene qPCR Shows Lower Detection Limit in Comparison to Single-Copy Gene in DNA Extracted from Purified Organisms, Chigger-Mites and Chigger-Mite Infected Mouse Liver

The purity of 15 strains of Orientia extracted from individual whole cell suspension was measured by Nanodrop spectrophotometer. Each DNA preparation (200, 40, 8, 1.6 or 0.32 copies Orientia GE per reaction) was analyzed for the $47 \mathrm{kDa}$ and traD genes. The $47 \mathrm{kDa}$ gene qPCR could not detect any 0.32 copies Orientia GE replicates and only detected some 1.6 copies Orientia GE replicates. The range of $\Delta \mathrm{Ct}$ (Table 1) was from as low as five to as high as $\sim 12$, suggesting the copy number of $t r a D$ varies in different strains and it could be as low as 32 copies per GE or as high as more than 1000 copies per GE. This was similarly observed when the DNA was extracted from two different chigger-mites and from mouse liver (Figure $1 \mathrm{~A}$ ). The $\Delta \mathrm{Ct}$ obtained from chigger-mites Lc was not significantly different from that of chigger-mites Li (Figure 1B). The results in Table 2 confirm that the traD gene qPCR provided more consistent results when the Orientia genome equivalent was really low. It was clear that the traD gene qPCR consistently showed lower $\mathrm{Ct}$ in comparison to the $47 \mathrm{kDa}$ gene qPCR. Additionally, at 0.4 copy $/ \mu \mathrm{L}$, only two out of seven samples showed detectable $47 \mathrm{kDa}$ gene and both had $C t$ values close to 35 . In contrast, the traD gene qPCR was able to detect all seven samples with very tight $\mathrm{Ct}$ values ranging from 30.2 to 30.5. The $\Delta \mathrm{Ct}$ among the three sets of extracted DNA was not statistically significant.

Table 2. Superior sensitivity of traD qPCR was demonstrated using purified genomic DNA spiked in normal human plasma *.

\begin{tabular}{|c|c|c|}
\hline & Sample 1 & Sample 2 \\
\hline Original DNA preparation (copy/ $\mu \mathrm{L}$ in $200 \mu \mathrm{L}$ NHS) & 0.4 & 10 \\
\hline Extracted DNA (copy $/ \mu \mathrm{L}$ in $50 \mu \mathrm{L}$ water) & 1.6 & 40 \\
\hline expected copy \# in a $\mathrm{qPCR}$ reaction ${ }^{\mathrm{a}}$ & $3.2(4.7,5.9)$ & $80(31.3 \pm 15.4)$ \\
\hline$\% 47 \mathrm{kDa}$ qPCR positive (range of Ct) ${ }^{b}$ & $28.6 \%(33.7,34.1)$ & $100 \%(30.3-33.3)$ \\
\hline$\%$ traD qPCR positive (range of $\mathrm{Ct}$ ) & $100 \%(30.2-30.5)$ & $100 \%(25.2-26.1)$ \\
\hline$\Delta \mathrm{Ct}$ & $3.62^{\mathrm{c}}$ & $5.66 \pm 0.65$ \\
\hline
\end{tabular}

\begin{abstract}
* The copy number of the $47 \mathrm{kDa}$ gene in the purified Karp strain Orientia was determined by qPCR. This copy number was used to calculate the amount of purified Orientia DNA needed to add to the $200 \mu$ Lnormal human plasma to achieve the desired concentration (i.e., 0.4 copy $/ \mu \mathrm{L}$ or 10 copies $/ \mu \mathrm{L}$ ) for DNA extraction. Normal human plasma without spiked Orientia DNA was extracted simultaneously and showed no detectable signals. ${ }^{\text {a. }}$ Numbers represent the expected copy number of the $47 \mathrm{kDa}$ gene using $2 \mu \mathrm{L}$ of extracted DNA in a qPCR reaction. Numbers in parentheses represent the actual copy number of the $47 \mathrm{kDa}$ gene determined by qPCR from individual replicates or as mean \pm standard deviation. The $47 \mathrm{kDa}$ gene $\mathrm{qPCR}$ was considered positive if the melting curve was consistent with positive controls. ${ }^{\mathrm{b}}$. A total of seven replicates of each concentration of Orientia genomic DNA were prepared and analyzed by qPCR independently. The range of $\mathrm{Ct}$ or individual $\mathrm{Ct}$ listed were for positive samples only. c. Average of two $\triangle \mathrm{Ct}$ was presented because $\mathrm{Ct}$ values were determined in only two of the $47 \mathrm{kDa}$ qPCR experiments.
\end{abstract}

\section{2. traD Gene qPCR Is Specific in the Presence of Excessive Chigger-Mite or Mouse Liver DNA}

The traD gene qPCR is specific to Orientia as the presence of various Rickettsia DNA (R. typhi, R. conorii, $R$. rickettsii, $R$. belli, A. phagocytophilum) did not give any positive results (Figure S1). In addition, the $\Delta \mathrm{Ct}$ obtained from Lc-chigger-mites infected mouse liver showed similar values as that in Lc chigger mites (Figure 1A), confirming the notion that the presence of excessive DNA from different sources (i.e., chigger-mite vs. mouse) did not affect the specificity of the traD qPCR. $\triangle \mathrm{Ct}$ was not calculated from 0.32 copies/qPCR reaction replicate as none of the $47 \mathrm{kDa}$ gene qPCR gave positive results. In contrast, the traD qPCR results consistently showed $\mathrm{Ct}$ ranging from $32.75 \pm 0.27$ to $33.35 \pm 0.93$. 


\section{3. traD Gene qPCR Is Sensitive and Specific in Clinically Confirmed Scrub Typhus Positive and Negative Samples}

In order to determine if the traD gene qPCR is clinically useful with acceptable sensitivity and specificity, DNA from 21 clinical samples were used to detect the presence of the traD gene. Among these clinical samples, the diagnosis was made based on combined results of IFA and PCR. The samples were diagnosed as ST positive as long as IFA or PCR results were positive. More specifically, 10 of them were confirmed scrub typhus positive by $47 \mathrm{kDa}$ or $56 \mathrm{kDa}$ PCR and/or IFA with the exception of scrub typhus 10. This patient was confirmed as positive due to a seroconversion even though the acute sample tested in this study was PCR and IFA negative. Six samples of confirmed other infections and five samples of healthy individuals were also included. Table 3 shows that all positive samples were traD gene qPCR positive and all negatives were traD gene qPCR negative, demonstrating 100\% sensitivity and specificity (Table 4). It is worth noting that the traD qPCR results were consistent with the diagnosis based on the combined PCR and IFA results in spite of the fact that not all ST positive samples had consistent PCR and IFA results (e.g., scrub typhus 2, 3, 4, 5, 7, and 9). More specifically, using PCR results as the reference, the performance of traD qPCR was $100 \%$ sensitive and $73.3 \%$ specific due to identification of four negative PCR samples as positive (Table 4). Similarly, using IFA results as the reference, $\operatorname{traD}$ qPCR showed $100 \%$ sensitivity and $73.3 \%$ specificity (Table 4 ) because four samples were mis-identified as positive by traD qPCR. Furthermore, for patient scrub typhus 10 from which the acute sample was neither IFA nor PCR positive, this sample was traD qPCR positive. The fact that the traD gene qPCR was able to pick up four positives that were negative by prior PCR or by IFA suggest that the traD gene qPCR is more sensitive than either PCR or IFA to diagnose scrub typhus (Figure S2).

Table 3. Results of traD qPCR using clinical confirmed scrub typhus patient samples *.

\begin{tabular}{|c|c|c|c|}
\hline Sample & Based on Melting Curve & $\mathrm{Ct}$ & PCR/IFA Result of Acute Sample \\
\hline NHB1 & Neg. & 36.5 & $\operatorname{PCR}(-) \operatorname{IFA}(-)$ \\
\hline NHB2 & Neg. & Undetermined & $\operatorname{PCR}(-) \operatorname{IFA}(-)$ \\
\hline NHB3 & Neg. & 36.5 & PCR(-) IFA(-) \\
\hline NHB4 & Neg. & 38.0 & $\operatorname{PCR}(-) \operatorname{IFA}(-)$ \\
\hline NHB5 & Neg. & 38.5 & $\operatorname{PCR}(-) \operatorname{IFA}(-)$ \\
\hline Other Disease 1 & Neg. & Undetermined & PCR(-) IFA(-) \\
\hline Other Disease 2 & Neg. & Undetermined & $\operatorname{PCR}(-) \operatorname{IFA}(-)$ \\
\hline Other Disease 3 & Neg. & 38.4 & $\operatorname{PCR}(-) \operatorname{IFA}(-)$ \\
\hline Other Disease 4 & Neg. & Undetermined & $\operatorname{PCR}(-) \operatorname{IFA}(-)$ \\
\hline Other Disease 5 & Neg. & 36.8 & PCR(-) IFA(-) \\
\hline Other Disease 6 & Neg. & 35.5 & $\operatorname{PCR}(-) \operatorname{IFA}(-)$ \\
\hline Scrub typhus 1 & Pos. & 32.3 & $\operatorname{PCR}(+) \operatorname{IFA}(+)$ \\
\hline Scrub typhus 2 & Pos. & 25.8 & $\operatorname{PCR}(-) \operatorname{IFA}(+)$ \\
\hline Scrub typhus 3 & Pos. & 31.9 & $\operatorname{PCR}(-) \operatorname{IFA}(+)$ \\
\hline Scrub typhus 4 & Pos. & 32.4 & $\operatorname{PCR}(+) \operatorname{IFA}(-)$ \\
\hline Scrub typhus $5^{a}$ & Pos. & 38.3 & $\operatorname{PCR}(+) \operatorname{IFA}(-)$ \\
\hline Scrub typhus 6 & Pos. & 28.1 & $\operatorname{PCR}(+) \operatorname{IFA}(+)$ \\
\hline Scrub typhus 7 & Pos. & 30.2 & PCR(-) IFA(+) \\
\hline Scrub typhus 8 & Pos. & 30.3 & $\operatorname{PCR}(+) \operatorname{IFA}(+)$ \\
\hline Scrub typhus 9 & Pos. & 24.7 & $\operatorname{PCR}(+) \operatorname{IFA}(-)$ \\
\hline Scrub typhus $10^{b}$ & Pos. & 22.4 & $\operatorname{PCR}(-) \operatorname{IFA}(-)$ \\
\hline
\end{tabular}

*. The Ct values were reported as the average of duplicate run for each sample tested. ${ }^{\text {a. }}$ Scrub typhus 5 was diluted two-fold due to insufficient DNA volume to perform qPCR. ${ }^{b}$. This patient was diagnosed as scrub typhus positive by seroconversion between acute and convalescent samples. The sample used in the study is the acute sample that has negative result by PCR and IFA. 
Table 4. Comparison of sensitivity and specificity of traD qPCR using IFA, PCR or results of clinical diagnosis *.

\begin{tabular}{cccc}
\hline & \multicolumn{3}{c}{ Patients are ST Positive or Negative Based on the Results from } \\
\cline { 2 - 4 } & IFA & PCR & Clinical Diagnosis \\
\hline Sensitivity (\%) & 100 & 100 & 100 \\
Specificity (\%) & $73.3^{\mathrm{a}}$ & $73.3^{\mathrm{a}}$ & 100 \\
\hline
\end{tabular}

* A sample was diagnosed as clinical positive if either PCR was positive, IFA was positive or a four-fold IFA titer increase between acute and convalescent samples was observed. ${ }^{a}$. The specificity was statistically significantly different from that calculated using clinical diagnosis as the determinant of ST positive or negative. $(p<0.01)$.

\section{Discussion}

The results presented a compelling evidence that the traD gene is specific and sensitive to detect Orientia in clinical samples. The specificity was tested in various DNA of closely related bacteria [21] as well as in the presence of excessive amounts of host DNA (i.e., chigger, human, and mouse). The increased sensitivity was demonstrated by its consistent detection of low GE of Orientia when a sensitive $47 \mathrm{kDa}$ qPCR could not (Table 2). Furthermore, the increased sensitivity was corroborated by the detection of four clinically diagnosed scrub typhus cases in spite of prior negative PCR results (Tables 3 and 4). It is believed that the multiple-copy traD gene contributes to this increased sensitivity. Keller et al. [21] have employed traD gene in their quantitation of Orientia in different tissues in a footpad challenge mouse model. Our results were consistent with theirs. We have previously demonstrated a slight increase of sensitivity in LAMP reaction using multiple copy genes. This was evidenced by shortening the reaction time to produce sufficient detectable fluorescent amplicons [24]. Others have shown increased sensitivity in detection of Orientia DNA in patient samples using a multiplex qPCR targeting two different genes [22]. All these observations confirm that the improvement of sensitivity can be achieved by multiplexing of several single copy genes or targeting a multiple copy gene.

The specificity of the $t r a D$ qPCR was first confirmed by performing BLAST search to determine the primers used were specific to Orientia [21]. The in silico results showed no cross-reactivity with genes of organisms that are phylogenetically close to Orientia. These in silico results were confirmed as no amplicons were observed when other sources of DNA were used. The presence of large amounts of other sources of DNA in the presence of low copy Orientia DNA did not affect specific detection of Orientia (Figure 1). Additionally, presence of DNA from chigger-mites, mouse, or human did not affect the observed $\Delta \mathrm{Ct}$ between the $47 \mathrm{kDa}$ and traD genes.

The inclusion of clinically diagnosed scrub typhus cases highlighted the clinical relevance of this sensitive qPCR assay. This was evident by the $100 \%$ sensitivity and specificity using a limited number of DNA extracted from well-defined clinical samples. More importantly, the traD qPCR was able to detect Orientia DNA with high confidence in those samples that were clinically diagnosed as scrub typhus in spite of negative PCR results. This finding demonstrated that the traD qPCR offered superior sensitivity to detect low copy number of Orientia that was otherwise undetectable using well accepted $47 \mathrm{kDa}$ or $56 \mathrm{kDa}$ gene-based PCR. This is particularly important as the circulating Orientia in blood is shown to be extremely low with a median of 13 copies $/ \mathrm{mL}$ in blood in 155 patients evaluated [15]. While it is possible to extract DNA from larger volumes of blood to increase the overall load of Orientia for qPCR, it is not always possible in all clinical settings. It is thus conceivable that when limited volume of a blood sample is available for PCR or qPCR, insufficient amount of Orientia DNA extracted from the sample may lead to false negative results. In our Orientia infection mouse model, we have compared the tissues collected on different days post infection and found that the traD gene qPCR was able to detect DNA in these tissues earlier in the time course in comparison to that detection by the $47 \mathrm{kDa}$ qPCR (data not shown), making this a sensitive assay in animal studies to monitor the quantity of Orientia as disease progresses; this is similarly observed by Keller et al. [21]. This could be 
an important improvement for diagnosis of scrub typhus during early phase of disease in vivo. The results in Table 3 support this notion.

While the traD qPCR appears to be more sensitive with sufficient specificity, an evaluation of its clinical performance using additional confirmed scrub typhus positive and negative samples is warranted. The inclusion of patients diagnosed with known scrub typhus co-circulating diseases is also recommended. A limited number of clinical samples for evaluation was one of the limitations of current study. Nevertheless, we successfully demonstrated that the traD qPCR offers superior sensitivity and specificity which could significantly improve the molecular detection of Orientia DNA. Additionally, it is worthwhile to develop isothermal assays such as LAMP or RPA so that the assay may have its field applicability in resource-limited areas where qPCR instruments are not always available.

\section{Conclusions}

We demonstrated that the traD qPCR was sensitive and specific for the detection of Orientia without interference from larger quantity of chigger-mites, mouse, or human genomes. The small scope evaluation using limited clinical samples clearly confirmed the clinical utility of this qPCR assay for sensitive detection of Orientia DNA. The increased sensitivity to detect Orientia DNA will improve diagnosis and consequently disease outcomes.

Supplementary Materials: The following are available online at http://www.mdpi.com/2414-6366/4/3/113/s1: Figure S1: Amplification of traD gene was specific to the presence of Orientia DNA., Figure S2: Consistent melting curve was observed only in clinically diagnosed scrub typhus positive samples.

Author Contributions: W.-M.C. conceived the study. T.B. and Z.Z. performed the experiments. C.-C.C. and L.J. analyzed and interpreted data. C.-C.C. wrote the manuscript with contributions from all authors.

Funding: This work was supported by work unit number 6000.RAD1.J.A0310 with funding from the Military Infectious Diseases Research Program (MIDRP) to W.M.C.

Acknowledgments: The study protocol (PN \#12-12) was reviewed and approved by the AFRIMS Institutional Animal Care and Use Committee in compliance with all applicable federal regulations governing the protection of animals and research. The non-human subject determination (PJT-15-15) was reviewed and determined by the Naval Medical Research Center (NMRC) Institutional Review Board in compliance with all applicable federal regulations governing the protection of human subjects. C.-C.C. and W.-M.C. are US Government employees and the work of these individuals was prepared as part of official government duties. Title 17 U.S.C. $\$ 105$ provides that "copyright protection under this title is not available for any work of the United States Government." Title 17 U.S.C. \$101 defines a U.S. Government work as a work prepared by a military service member or employee of the U.S. Government as part of that person's official duties. The views expressed are those of the authors and do not necessarily reflect the official policy or position of the Department of the Navy, Department of the Army, Department of Defense, nor the U.S. Government.

Conflicts of Interest: The authors declare no conflict of interest.

\section{References}

1. Bonell, A.; Lubell, Y.; Newton, P.N.; Crump, J.A.; Paris, D.H. Estimating the burden of scrub typhus: A systematic review. PLoS Negl. Trop. Dis. 2017, 11, e0005838. [CrossRef] [PubMed]

2. Xu, G.; Walker, D.H.; Jupiter, D.; Melby, P.C.; Arcari, C.M. A review of the global epidemiology of scrub typhus. PLoS Negl. Trop. Dis. 2017, 11, e0006062. [CrossRef] [PubMed]

3. Suttinont, C.; Losuwanaluk, K.; Niwatayakul, K.; Hoontrakul, S.; Intaranongpai, W.; Silpasakorn, S.; Suwancharoen, D.; Panlar, P.; Saisongkorh, W.; Rolain, J.M.; et al. Causes of acute, undifferentiated, febrile illness in rural Thailand: Results of a prospective observational study. Ann. Trop. Med. Parasitol. 2006, 100, 363-370. [CrossRef] [PubMed]

4. Phongmany, S.; Rolain, J.M.; Phetsouvanh, R.; Blacksell, S.D.; Soukkhaseum, V.; Rasachack, B.; Phiasakha, K.; Soukkhaseum, S.; Frichithavong, K.; Chu, V.; et al. Rickettsial infections and fever, Vientiane, Laos. Emerg. Infect. Dis. 2006, 12, 256-262. [CrossRef] [PubMed]

5. Kasper, M.R.; Blair, P.J.; Touch, S.; Sokhal, B.; Yasuda, C.Y.; Williams, M.; Richards, A.L.; Burgess, T.H.; Wierzba, T.F; Putnam, S.D.; et al. Infectious etiologies of acute febrile illness among patients seeking health care in south-central Cambodia. Am. J. Trop. Med. Hyg. 2012, 86, 246-253. [CrossRef] [PubMed] 
6. Kelly, D.J.; Richards, A.L.; Temenak, J.; Strickman, D.; Dasch, G.A. The past and present threat of Rickettsial diseases to military medicine and international publich health. Clin. Infect. Dis. 2002, 34 (Suppl. S4), S145-S169. [CrossRef] [PubMed]

7. Taylor, A.J.; Paris, D.H.; Newton, P.N. A Systematic Review of Mortality from Untreated Scrub Typhus (Orientia tsutsugamushi). PLoS Negl. Trop. Dis. 2015, 9, e0003971. [CrossRef]

8. Varghese, G.M.; Abraham, O.C.; Mathai, D.; Thomas, K.; Aaron, R.; Kavitha, M.L.; Mathai, E. Scrub typhus among hospitalised patients with febrile illness in South India: Magnitude and clinical predictors. J. Infect. 2006, 52, 56-60. [CrossRef]

9. Izzard, L.; Fuller, A.; Blacksell, S.D.; Paris, D.H.; Richards, A.L.; Aukkanit, N.; Nguyen, C.; Jiang, J.; Fenwick, S.; Day, N.P.; et al. Isolation of a novel Orientia species (O. chuto sp. nov.) from a patient infected in Dubai. J. Clin. Microbiol. 2010, 48, 4404-4409. [CrossRef]

10. Balcells, M.E.; Rabagliati, R.; Garcia, P.; Poggi, H.; Oddo, D.; Concha, M.; Abarca, K.; Jiang, J.; Kelly, D.J.; Richards, A.L.; et al. Endemic scrub typhus-like illness, Chile. Emerg. Infect. Dis. 2011, 17, 1659-1663. [CrossRef]

11. Weitzel, T.; Dittrich, S.; Lopez, J.; Phuklia, W.; Martinez-Valdebenito, C.; Velasquez, K.; Blacksell, S.D.; Paris, D.H.; Abarca, K. Endemic scrub typhus in South America. N. Engl. J. Med. 2016, 375, 954-961. [CrossRef] [PubMed]

12. Ghrobani, R.P.; Ghorbani, A.J.; Jain, M.K.; Walker, D.H. A Case of Scrub Typhus Probably Acquired in Africa. Clin. Infect. Dis. 1997, 25, 1473-1474. [CrossRef] [PubMed]

13. Jiang, J.; Chan, T.C.; Temenak, J.; Dasch, G.; Ching, W.M.; Richards, A.L. Development of a quantitative real-time polymerase chain reaction assay specific for Orientia tsutsugamushi. Am. J. Trop. Med. Hyg. 2004, 70, 351-356. [CrossRef] [PubMed]

14. Silpasakorn, S.; Srisamut, N.; Ekpo, P.; Zhang, Z.; Chao, C.C.; Ching, W.M.; Suputtamongkol, Y. Development of new, broadly reactive, rapid IgG and IgM lateral flow assays for diagnosis of scrub typhus. Am. J. Trop. Med. Hyg. 2012, 87, 148-152. [CrossRef] [PubMed]

15. Sonthayanon, P.; Chierakul, W.; Wuthiekanun, V.; Phimda, K.; Pukrittayakamee, S.; Day, N.P.; Peacock, S.J. Association of high Orientia tsutsugamushi DNA loads with disease of greater severity in adults with scrub typhus. J. Clin. Microbiol. 2009, 47, 430-434. [CrossRef] [PubMed]

16. Paris, D.H.; Aukkanit, N.; Jenjaroen, K.; Blacksell, S.D.; Day, N.P. A highly sensitive quantitative real-time PCR assay based on the groEL gene of contemporary Thai strains of Orientia tsutsugamushi. Clin. Microbiol. Infect. 2009, 15, 488-495. [CrossRef] [PubMed]

17. Evans, S.M.; Adcox, H.E.; VieBrock, L.; Green, R.S.; Luce-Fedrow, A.; Chattopadhyay, S.; Jiang, J.; Marconi, R.T.; Paris, D.; Richards, A.L.; et al. Outer membrane protein a conservation among orientia tsutsugamushi isolates suggests its potential as a protective antigen and diagnostic target. Trop. Med. Infect. Dis. 2018, 3, 63. [CrossRef] [PubMed]

18. Huber, E.; Ji, D.; Howell, L.; Zhang, Z.; Chen, H.C.; Ching, W.M.; Chao, C.C. Loop-Mediated Isothermal Amplification Assay Targeting the 47-Kda Gene of Orientia tsutsugamushi: A rapid and sensitive alternative to real-time PCR. J. Med. Microbiol. Diagn. 2012, 1, 112. [CrossRef]

19. Blacksell, S.D.; Paris, D.H.; Chierakul, W.; Wuthiekanun, V.; Teeratakul, A.; Kantipong, P.; Day, N.P. Prospective evaluation of commercial antibody-based rapid tests in combination with a loop-mediated isothermal amplification PCR assay for detection of Orientia tsutsugamushi during the acute phase of scrub typhus infection. Clin. Vaccine Immunol. 2012, 19, 391-395. [CrossRef]

20. Chao, C.C.; Belinskaya, T.; Zhang, Z.; Ching, W.M. Development of recombinase polymerase amplification assays for detection of Orientia tsutsugamushi or rickettsia typhi. PLoS Negl. Trop. Dis. 2015, 9, e0003884. [CrossRef]

21. Keller, C.A.; Hauptmann, M.; Kolbaum, J.; Gharaibeh, M.; Neumann, M.; Glatzel, M.; Fleischer, B. Dissemination of Orientia tsutsugamushi and inflammatory responses in a murine model of scrub typhus. PLoS Negl. Trop. Dis. 2014, 8, e3064. [CrossRef] [PubMed]

22. Tantibhedhyangkul, W.; Wongsawat, E.; Silpasakorn, S.; Waywa, D.; Saenyasiri, N.; Suesuay, J.; Thipmontree, W.; Suputtamongkol, Y. Use of multiplex real-time PCR to diagnose scrub typhus. J. Clin. Microbiol. 2017, 55, 1377-1387. [CrossRef] [PubMed] 
23. Ching, W.M.; Lurchachaiwong, W.; Zhang, Z.; Awoyomi, T.; Chao, C.C.; Schuster, A. Evaluation of a recombinant vaccine candidate r56Lc-1 in a chigger challenge mouse model. J. Vaccines Vaccin 2014, 5. [CrossRef]

24. Chao, C.C. Rapid and sensitive detection of Orientia tsutsugamushi DNA using loop mediated isothermal amplification (LAMP). In Proceedings of the JITMM 2010 and IMC 2010. Centara Grand and Bangkok Convention Centre at Central World, Bangkok, Thailand, 1-3 December 2010. 